\title{
Editorial
}

\section{Coronary heart disease trends in France and elsewhere}

In this issue the MONICA (monitoring trends and determinants in cardiovascular disease) team from Toulouse reports on myocardial infarction trends in south west France between 1985 and 1993. ${ }^{1}$ There were 3263 events in men and there appeared to be an annual decrease of around $2 \%$ in both event rate and mortality rates. Twenty eight day case fatality fell by about 3\% per year for first events and by $6 \%$ for recurrent events. The confidence intervals, however, are very wide around these estimates. The authors have concluded that the decrease in myocardial infarction mortality was predominantly attributable to reduction in case fatality and, by inference, improvements in acute management. It should be noted that there were few events in women. ${ }^{1}$

The Toulouse report updates an earlier description of the same population for the period $1985-90,{ }^{2}$ and provides local detail as part of the much larger MONICA project recently reported elsewhere. ${ }^{3}$ Curiously, the attack rates and case fatality rates in the present report are quite different from those in the earlier one. ${ }^{2}$ In the overall MONICA analysis, 10 year trends in 37 populations highlighted mortality declines in the majority and substantial declines in 12 populations. ${ }^{3}$ In men, the annual mean change in coronary event rates averaged $4.3 \%$ compared with only $2.1 \%$ reduction in case fatality, an overall pattern very different from the Toulouse experience. Another curiosity, however, is that the main MONICA report seems to show the pattern of change in Toulouse in keeping with the overall findings and, therefore, not as in the present report. ${ }^{13}$ Having noted the substantial contributions from changes in survival, the MONICA investigators emphasised that "the major determinants of decline in CHD [coronary heart disease] mortality is whatever drives changing coronary event rates". ${ }^{3}$

The Toulouse paper highlights five key issues: trends in event rates, trends in mortality, trends in case fatality, inferences about treatment effects (secondary prevention), and inferences about cardiovascular risk factors (primary prevention). ${ }^{1}$ Coronary heart disease mortality statistics are the epidemiological rock to which all other phenomena can be most safely tied ${ }^{4}$. One of the great achievements of the MONICA programme has been the general validation of routine mortality statistics across the majority of the 21 countries. It is perhaps not surprising that two of the lowest coronary heart disease mortality rates are reported in Japan and in France where substantial numbers of coronary deaths are coded as something else. ${ }^{5}$ However, the general trends are clear. In the majority of industrialised countries coronary heart disease mortality has fallen by a third or a half in the last two decades. Falls have been steeper in younger age groups and more affluent social classes. ${ }^{36}$ Trends in myocardial infarction and coronary heart disease event rates have generally mirrored trends in mortality. Various reports of increases in non-fatal acute myocardial infarction rates have a complex explanation which includes a reduction in hospital admission thresholds, an increase in the sensitivity of enzyme diagnostic tests, and financial pressures to recode non-specific coronary disease as frank acute myocardial infarction. ${ }^{7}$

Trends in case fatality are easier to describe than to explain. The majority of reports from the USA, UK,
Europe, and Australasia show substantial reductions in case fatality. $^{3}{ }^{7-10}$ The Nottingham series represents a major exception. ${ }^{11}$ Because case fatality is the ratio between death and total events, it remains vulnerable to denominator expansion. Meticulous and consistent definitions therefore become crucial. ${ }^{78}$ However, both short term and long term case fatality after acute myocardial infarction remain substantial and individual treatments achieve relative mortality reductions of only $20 \%$ or $30 \% .^{6}$ Thus in every 100 patients admitted with an acute myocardial infarction, no more than five deaths might be expected to be prevented or postponed by the combination of thrombolysis and aspirin, for instance. ${ }^{12}$

Most other epidemiological studies also suggest that a decline in event rates and, by implication, primary and secondary prevention, contributes at least as much, if not more, to the reduction in coronary mortality in developed countries. Indeed, this is the conclusion of the overall MONICA study ${ }^{3}$ and appears to have been true of Toulouse during the period covered in the principal MONICA report. ${ }^{2}$ Furthermore, when the combined effects of cardiological treatments are modelled in Australasia, USA, or Europe, they generally can explain no more than half of the mortality reduction. ${ }^{6}{ }^{13} 14$ These same models suggest that a larger mortality reduction is attributable to falls in the major cardiovascular risk factorssmoking, cholesterol, and blood pressure. ${ }^{6}{ }^{13} 14$

In conclusion, the totality of the epidemiological data supports strong policy initiatives on both primary and secondary prevention. ${ }^{36}{ }^{13}$ Cardiovascular risk factors can be reduced in entire populations through comprehensive and integrated prevention programmes. ${ }^{15}$ Furthermore, in patients with established coronary heart disease, there is extensive evidence on the effectiveness and cost effectiveness of secondary preventive cardiological treatments, and correspondingly strong arguments for increasing treatment levels from $40 \%$ to at least $80 \%$ of eligible patients ${ }^{16}$ and, in Britain at least, unequivocal government support. ${ }^{17}$ Undoubtedly, optimum treatment of acute myocardial infarction is also of the upmost importance. The scourge of coronary heart disease continues to require a multifaceted attack.

\section{SIMON CAPEWELL} JOHN MCMURRAY

MRC Clinical Research Initiative in Heart Failure,

Wolfson Building (Level 3),

University of Glasgow.

Glasgow G12 8QQ, UK

email:j.mcmurray@bio.gla.ac.uk

1 Marques-Vidal P, Ruidavets J-B, Cambou J-P, et al. Incidence, recurrence, and case fatality rates for myocardial infarction in southwestern France, 1985 to 1993 . Heart $2000 ; 84: 171-5$

2 Ferrieres J, Cambou J-P, Ruidavets J-B, et al. Trends in acute myocardial infarction prognosis and treatment in southwestern France between 1985 and 1990 (the MONICA project-Toulouse). Am F Cardiol 1995;75:1202-5.

3 Tunstall-Pedoe $\mathrm{H}$, Kuulasmaa $\mathrm{K}$, Mähönen $\mathrm{M}$, et al, for the WHO MONICA (monitoring trends and determinants in cardiovascular disease) project contribution of trends in survival and coronary-event rates to project contribution of trends in survival and coronary-event rates to MONICA project populations. Lancet 1999;353:1547-57.

4 Capewell S, Perry A, Walker A, et al. Using option appraisal to evaluate the costs and benefits of heart disease monitoring. Heart In press.

5 Law M, Wald N, Stampfer M, et al. Why heart disease mortality is low in France: the time lag explanation. BMF 1999;318:1471-80. 
6 Capewell S, Morrison CE, McMurray JJV. Contribution of modern cardiovascular treatment to the decline in coronary heart disease mortality in Scotland between 1975 and 1994 . Heart 1999:81:380-7.

7 Capewell S, Kendrick S, Boyd J, et al. Measuring outcomes: one month survival after acute myocardial infarction in Scotland. Heart 1996;76:70-5.

8 Tunstall-Pedoe H, Vanuzzo D, Hobbs $M$, et al, for the WHO MONICA Project. Estimation of contribution of changes in coronary care to improving survival, event rates, and coronary heart disease mortality across the WHO MONICA project populations. Lancet 2000;355:688-700.

9 Capewell S, Livingston M, MacIntyre K, et al. Mortality trends in 178,000 patients admitted with acute myocardial infarction. Heart 1999;81:(suppl 1):27.

10 Gottlieb S, Goldbourt U, Boyko V, et al. Mortality trends in men and women with acute myocardial infarction in coronary care units in Israel. Eur Heart 7 2000;21:284-95.

11 Brown $\mathrm{N}$, Young $\mathrm{T}$, Gray D, et al. Inpatient deaths from acute myocardial infarction, 1982-92: analysis of data in the Nottingham heart attack register. BMF 1997;315:159-64.
12 Appleby P, Baigent C, Collins R, et al. Indications for fibrinolytic therapy in suspected acute myocardial infarction: collaborative overview of early morsuspected acute myocardial infarction: collaborative overview of early mortality and major morbidity results from

13 Hunink MGM, Goldman L, Tosteson ANA, et al. The recent decline in mortality from coronary heart disease, 1980-1990: the effect of secular trends in risk factors and treatment. $\mathcal{F} A M A 1997 ; 277: 535-42$

14 Capewell S, Beaglehole R, Seddon M, et al. Contribution of modern treatment to the decline in coronary heart disease mortality in New Zealand, 1982-93. F Epidemiol Community Health 1998;52:691

15 Capewell S, McEwen J, Dunbar J, et al. Effects of the Heartbeat Wales programme: programme that originated in Finland should be adopted. BMf 1999;318:1072-3.

16 Capewell S, Pell J, Morrison CE, et al. Increasing the impact of cardiological treatments: how best to reduce deaths. Eur Heart f 1999;20:1386-92.

17 Anon. National Service Framework for Coronary Heart Disease. Modern standards and service models. London: Department of Health, March 2000.

\section{IMAGES IN CARDIOLOGY}

\section{Descending thoracic aortic aneurysm in rheumatoid arthritis}
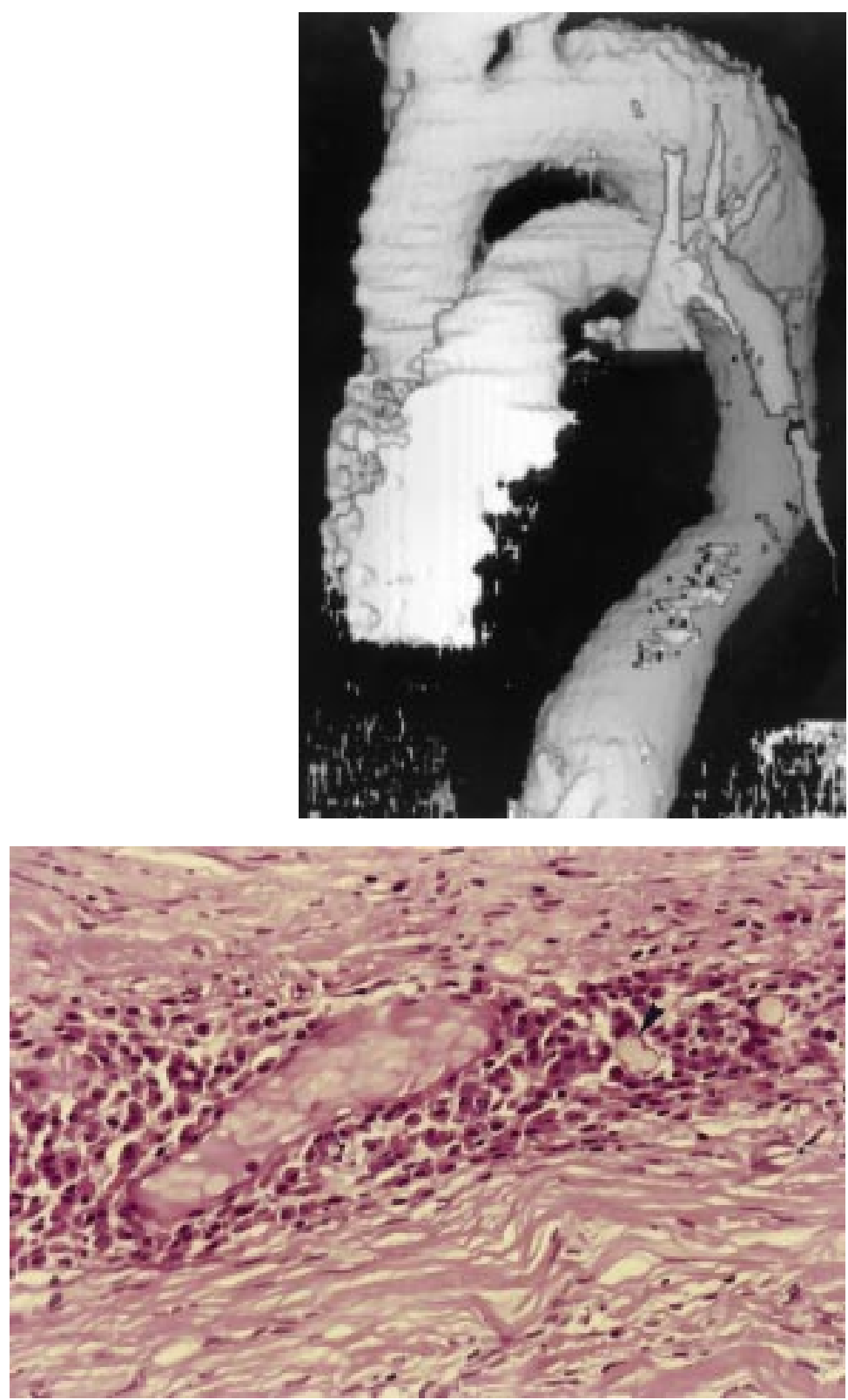

A 55 year old normotensive male smoker with seropositive nodular erosive rheumatoid arthritis (rheumatoid factor 390, normal range 0-20 $\mathrm{IU} / \mathrm{ml}$ ), controlled on sulfasalazine and indometacin, had a thoracic aortic aneurysm detected on routine chest radiography. Computed tomography (CT), with spiral reconstruction, confirmed that this started immediately distal to the left subclavian artery and was $7 \mathrm{~cm}$ in diameter and $13 \mathrm{~cm}$ in length. Just above the diaphragm the aorta began to dilate again, and at the level of the renal hilum was $4.5 \mathrm{~cm}$ in diameter. The thoracic aneurysm was resected and replaced with a $32 \mathrm{~mm}$ knitted polyester graft impregnated with gelatin.

Histology of the resected aorta (haematoxylin and eosin stain, original magnification $\times 100$ ) showed features consistent with rheumatoid vasculitis with a panmural aortitis and an inflammatory cell infiltrate comprising mainly plasma cells and lymphocytes. There was distortion and thinning of the elastic media and adventitial fibrosis. The vasa vasorum showed a dense perivascular cuff of lymphocytes with Russell bodies, which represent deposits of immune complexes (arrowed).

Vasculitis occurs in fewer than $1 \%$ of patients with rheumatoid arthritis and usually only in those with severe deforming rheumatoid arthritis and high titres of rheumatoid factor. Large vessel involvement with aortitis occurs in 5\% of patients with rheumatoid vasculitis. Aneurysm formation secondary to rheumatoid vasculitis is extremely rare and then usually affects the aortic root and ascending aorta.

P MODI

K SUVARNA

G J COOPER 